\title{
CHROMATOGRAPHIC SEPARATION OF REDUCING SUGARS IN THE URINES OF NEWBORN BABIES
}

BY

\author{
J. C. HAWORTH and DAVID MCCREDIE \\ From the Children's Hospital, Sheffield \\ (RECEIVED FOR PUBLICATION JANLARY 23, 1956)
}

The application of paper chromatography to the qualitative analysis of reducing sugars by Partridge (1946) has greatly simplified the detection of these substances in biological fluids. In particular it has provided an accurate and comparatively easy method of separating reducing sugars in the urine. This has proved of great value in the investigation of such a condition as congenital galactosaemia, about which disease there has been much recent interest (Bray, Isaac and Watkins, 1952; Hudson, Ireland, Ockenden and White-Jones, 1954; Cox and Pugh, 1954). It is now almost a routine procedure for the urine of a baby becoming ill with jaundice in the first few days of life and not thriving to be tested for reducing substances. Hudson and Ireland (1954) have, however, warned against reaching a hasty diagnosis of galactosaemia if galactose is found in the urine of such a baby.

There is little information in the literature about the physiological excretion of reducing sugars by newborn babies. Woolf (1951) said that small amounts of galactose and lactose are found in the urines of milk-fed infants, but he gave no figures. $\mathrm{He}$ also said that xylose is frequently present in normal urines, but rarely exceeds $3 \mathrm{mg} . / 100 \mathrm{ml}$. Rubin (1954) stated that sugars may be found in small amounts in the urines of healthy infants in the early months of life, but he gave no details. Flynn, Harper and de Mayo (1953) found lactose in the urines of $9 \%$ of normal men and women.

This paper is a report of our findings of the examination by paper chromatography of the urines of 50 normal male babies.

\section{Method}

Specimens of urine were collected from an unselected group of $\mathbf{5 0}$ male babies born at full term at the Jessop Hospital for Women, Sheffield. All urines were collected within the first seven days of life.

The chromatographic technique employed was that described by Williams (1954), using triangular-shaped filter paper, a butanol-pyridine solvent and a benzidine reagent developer.

A standard solution containing known amounts of glucose, galactose, lactose and xylose was put up with each set of urines and an approximate quantitative estimation of the reducing sugars in the urines was made by comparing the depth of colour produced on the filter paper after it had been developed with that produced by the known concentrations of the sugars. If a urine specimen could not be chromatographed on the day on which it was collected, thymol was added and it was stored at $-20=\mathrm{C}$. Each urine was also tested with Benedict's qualitative reagent.

All 50 babies were breast fed. For the first two days of life they were put to the breast at approximately six-hour intervals, and after that feeding was 'by demand'. Occasionally glucose water was given in the first two days if a baby seemed thirsty. It was not possible to correlate the times of feeding with the times that the urines were collected.

Results
Eighty-one urines were collected from the 50 babies.

Twenty-two babies (from whom 34 urines were collected) showed no reducing sugar in any specimen. Four babies (five urines) showed an unidentified reducing substance only. Twenty-four babies (42 urines) showed one or more reducing sugar in 25 specimens.

Six urines contained less than $50 \mathrm{mg}$. lactose $100 \mathrm{ml}$., five contained $50-100 \mathrm{mg}$. lactose $/ 100 \mathrm{ml}$. and four $100-250 \mathrm{mg}$. lactose $/ 100 \mathrm{ml}$. Seven urines contained less than $50 \mathrm{mg}$. galactose $/ 100 \mathrm{ml}$., and six $50-100 \mathrm{mg}$. galactose $/ 100 \mathrm{ml}$. Three urines contained less than $50 \mathrm{mg}$. xylose $/ 100 \mathrm{ml}$. and one $50-100 \mathrm{mg}$. xylose $/ 100 \mathrm{ml}$. Seven urines contained two sugars each. Nine urines contained an unidentified reducing substance. Glucose was not identified in any of the urines examined. Four urines reduced Benedict's reagent to yellow or orange and three of these were specimens containing $100-250 \mathrm{mg}$. $/ 100 \mathrm{ml}$. of lactose, the other contained less than $50 \mathrm{mg}$. $/ 100 \mathrm{ml}$. of xylose and an unidentified reducing substance.

Table 1 shows the number of babies who excreted lactose, galactose and xylose or combinations of the sugars. Table 2 shows the ages of the babies when the urines were examined. 
TABLE 1

NUMBER OF BABIES EXCRETING REDUCING SUGARS

\begin{tabular}{|c|c|c|c|}
\hline Reducing Sugar & & & No. of Babies \\
\hline $\begin{array}{l}\text { Lactose } \ldots \\
\text { Galactose } \ldots \\
\text { Lactose and galactose } \\
\text { Xylose } \\
\text { Xylose and lactose }\end{array}$ & $\begin{array}{l}\cdots \\
\cdots \\
\cdots \\
\ldots\end{array}$ & $\begin{array}{c}\cdots \\
\cdots \\
\cdots \\
\cdots\end{array}$ & $\begin{array}{r}14 \\
13 \\
6 \\
4 \\
1\end{array}$ \\
\hline
\end{tabular}

TABLE 2

AGES OF 50 BABIES WHEN URINES WERE EXAMINED

\begin{tabular}{|c|c|c|c|c|c|c|c|}
\hline & \multicolumn{7}{|c|}{ Day of Age in Babies Examined } \\
\hline & 1st & 2nd & 3rd & 4th & 5th & 6th & 7th \\
\hline $\begin{array}{l}\text { No. of urines containing } \\
\text { lactose }\end{array}$ & 1 & & 5 & 1 & 7 & 1 & \\
\hline $\begin{array}{l}\text { No. of urines containing } \\
\text { galactose }\end{array}$ & & & 4 & 1 & 6 & 1 & 1 \\
\hline $\begin{array}{l}\text { No. of urines containing } \\
\text { xylose ... }\end{array}$ & & & 3 & & 1 & & \\
\hline $\begin{array}{l}\text { Total no. of urines con- } \\
\text { taining reducing sugars } \\
\text { No. of urines containing }\end{array}$ & 1 & $\mathbf{0}$ & $9^{*}$ & 2 & $10^{*}$ & 2 & 1 \\
\hline $\begin{array}{l}\text { no reducing sugar } \\
\text { Total no. of urines }\end{array}$ & 14 & 6 & 10 & 3 & 9 & 5 & 9 \\
\hline examined $\quad \ldots \quad \ldots$ & 15 & 6 & 19 & 5 & 19 & 7 & 10 \\
\hline
\end{tabular}

* Three third-day and three fifth-day urines contained both lactose and galactose. One fifth-day urine contained both lactose and xylose.

\section{Discussion}

As shown above, 24 out of 50 normal male babies excreted a reducing sugar at some time during the first seven days of life, and four babies excreted relatively large amounts of lactose $(100-250 \mathrm{mg}$./ $100 \mathrm{ml}$.); the urines of three of these babies reduced Benedict's reagent to yellow or orange. Our numbers are too small for any firm conclusion to be reached, but Table 2 shows that the sugars were excreted mainly on the third to the fifth days of life, and less sugars were found on the first, second, sixth and seventh days.

The source of the lactose and galactose in the urines of the babies was presumably the gut. Flynn et al. (1953) thought that this was the most likely source of the lactose which they found in the urines of normal men and women, although in pregnancy and the puerperium, when considerable lactosuria was found, they thought that the probable cause was the reabsorption of lactose from the secreting mammary glands into the blood. If the lactose and galactose which we found in the urines of our babies was of alimentary origin it is not surprising that only one out of 21 urines collected on the first and second day of life contained a sugar, because the babies' intake of milk on the first two days of life would be very small. The one baby that excreted lactose on the first day of life was put to the breast twice a day, but we do not know the time of collection of the specimen in relation to the feeds. By the third, fourth and fifth days of life the babies would be taking more from the breast and this is when the maximum number of sugars was found. Lactose is normally hydrolysed to glucose and galactose before absorption, and if it is absorbed unchanged it cannot be metabolized and is excreted by the kidney. Why hydrolysis should not occur we do not know; there is no evidence of a deficiency of lactase in mature infants (Smith, 1951).

Galactose after absorption from the gut is usually metabolized to glycogen in the liver, but Hartmann, Grunwaldt and James (1953) have shown that in infants after milk feeds as much as $40 \%$ of the blood sugar may be galactose. If the renal threshold for galactose was exceeded galactosuria would result. Tolerance to ingested galactose is used as a test of liver function (Roe and Schwartzman, 1933), and as it is known that the liver of the newborn is functionally inefficient (Yudkin, Gellis and Lappen, 1949) this factor may have played a part as a cause of the galactosuria. That this may be so is suggested by the finding of maximum excretion of sugars on the third to the fifth days of life when physiological jaundice, now thought to be the result of liver inefficiency (Mollison, 1948), is at its height. By the sixth and seventh days physiological jaundice has usually faded, indicating liver 'recovery' and it is of interest that we found fewer sugars on these days.

Xylose is not a constituent of milk and it is likely that in the four babies in whom this sugar was found it had an endogenous origin.

\section{Summary}

The urines of 50 normal male babies were examined for reducing sugars by paper chromatography.

Twenty-four babies excreted either lactose, galactose or xylose or a combination of these sugars at some time during the first seven days of life.

The possible cause of these findings is discussed.

We have much pleasure in thanking Professor R. A. McCance, F.R.S., and Dr. J. L. Emery for help and advice in the preparation of this paper. We also thank Miss E. Finch for biochemical facilities. The babies were under the care of Dr. T. Colver and Professor R. S. Illingworth to both of whom we are also grateful for their helpful criticism.

$$
\text { REFERENCES }
$$

Bray, P. T., Isaac, R. J. and Watkins, A. G. (1952). Archives of Disease in Childhood, 27, 341

Cox, P. J. N. and Pugh, R. J. P. (1954). Brit. med. J., 2, 613.

Flynn, F. V., Harper, C. and Mayo, P. de (1953). Lancet, 2, 698. Hartmann, A. F., Grunwaldt, E. and James, D. H. (1953). 'J. Pediat., $43,1$.

Hudson, F. P. and Ireland, J. T. (1954). Brit. med. J., 1, 647. -,$\frac{1}{1}$, Ockenden, B. G. and White-Jones, R. H. (1954). Ibid., $1,242$.

Mollison, P. L. (1948). Lancet, 1, 513

Partridge, S. M. (1946). Nature (Lond.), 158, 270.

Roe, J. H. and Schwartzman, A. S. (1933). Amer. J. med. Sci., $186,425$.

Rubin, M. I. (1954). In Textbook of Pediatrics, 6th ed., edited by Nelson, W. E., Philadelphia and London.

Smith, C. A. (1951). The Physiology of the Newborn Infant, 2nd ed. Oxford.

Williams, R. (1954). J. med. Lab. Technol., 12, 43.

Woolf, L. I. (1951). Gt Ormond St. J., 1, no. 2, p. 61.

Yudkin, S., Gellis, S. S. and Lappen, F. (1949). Archives of Disease in Childhood, 24, 12. 